\title{
SISTEM INFORMASI EVALUASI AKADEMIK MAHASISWA (STUDI KASUS PROGRAM STUDI ILMU KOMPUTER FAKULTAS MATEMATIKA DAN ILMU PENGETAHUAN ALAM UNIVERSITAS MULAWARMAN)
}

\author{
Alfadita Shany $^{1)}$, Dyna Marisa Khairina ${ }^{2)}$, Septya Maharani ${ }^{3)}$ \\ ${ }^{1,2,3)}$ Program Studi Ilmu Komputer, FMIPA, Universitas Mulawarman \\ Jalan Barong Tongkok No. 4 Kampus Gunung Kelua Sempaja Samarinda, Kalimantan Timur \\ E-Mail : shanyalfadita@gmail.com ${ }^{1)}$, dyna.ilkom@gmail.com ${ }^{2)}$, septyamaharani@yahoo.com ${ }^{3)}$
}

\begin{abstract}
ABSTRAK
Perkembangan ilmu pengetahuan di segala bidang dalam era globalisasi saat ini begitu pesat, terutama dalam bidang IT yang semakin maju seiring dengan kebutuhan pemakai untuk dapat mendukung atau mempermudah setiap kegiatan yang dilakukan di dalam bidang perkuliahan pada saat ini, terutama dalam setiap proses pemantauan status mahasiswa. Status mahasiswa bisa menjadi salah satu hal terpenting untuk membantu mengontrol tahapan capaian mahasiswa. Penelitian dengan judul Sistem Informasi Data Mahasiswa di Program Studi Ilmu Komputer Fakultas Matematika dan Ilmu Pengetahuan Alam Universitas Mulawarman ini bertujuan untuk membantu mengawasi kemajuan dan perkembangan kegiatan perkuliahan mahasiswa yang belum terkomputerisasi. Pengembangan aplikasi dilakukan dengan menggunakan bahasa pemprograman VB.Net dan metode Waterfall. Dari hasil implementasi aplikasi dapat disimpulkan bahwa aplikasi ini memberikan manfaat untuk membantu program studi untuk mengambil keputusan atau tindakan yang akan diberikan kepada mahasiswa melalui output yang akan dihasilkan oleh penelitian ini.
\end{abstract}

Kata kunci : Waterfall, Mahasiswa, Sistem, Informasi

\section{PENDAHULUAN}

Universitas merupakan perguruan tinggi sebagai institusi yang memiliki peran dan posisi strategis dalam pencapaian tujuan pendidikan secara makro yang perlu melakukan upaya perbaikan secara terus menerus untuk mewujudkan sumber daya manusia (SDM) yang berkualitas. Keberadaan manusia sebagai sumber daya sangat penting dalam suatu perguruan tinggi karena sumber daya manusia menunjang melalui karya, bakat, kreativitas, dorongan, dan peran nyata. Tanpa adanya unsur manusia dalam perguruan tinggi, tidak mungkin perguruan tinggi tersebut dapat bergerak dan menuju yang diinginkan.

Unsur manusia dalam universitas adalah mahasiswa yang berperan peserta didik pada jenjang pendidikan tinggi. Perguruan tinggi berkewajiban melaksanakan Tridharma Perguruan Tinggi. Tridharma adalah kewajiban perguruan tinggi untuk menyelenggarakan pendidikan, penelitian, dan pengabdian kepada masyarakat.

Kegiatan belajar mengajar merupakan kegiatan pendidikan wajib bagi para mahasiswa sebagai syarat memenuhi sebuah kegiatan perkuliahan. Agar mahasiswa dapat memenuhi persyaratan untuk menempuh tugas akhir (skripsi), mahasiswa harus menempuh kegiatan belajar mengajar beberapa mata kuliah, baik yang bersifat wajib maupun pilihan yang jumlahnya telah ditetapkan dalam Buku Pedoman Pendidikan Universitas Mulawarman dan jumlah mata kuliah dinyatakan dalam SKS (Satuan Kredit Semester), selain itu mahasiswa wajib mengikuti KKN (Kuliah Kerja Nyata) yang termasuk dalam Tridharma Perguruan Tinggi, dan PKL (Praktik Kerja Lapangan).

Mengetahui status mahasiswa dalam proses belajar mengajar sangat penting dalam sebuah kegiatan pendidikan. Status mahasiswa atau tahapan capaian berisikan informasi mengenai tahapan mana yang telah ditempuh mahasiswa, diantaranya meliputi apakah mahasiswa yang bersangkutan sudah melaksanakan seminar 1 (seminar proposal), PKL (Praktik Kerja Lapangan), pendadaran, dan juga lulus. Mengetahui status mahasiswa merupakan hal penting dalam kegiatan belajar mengajar agar pihak universitas pada umumnya dan fakultas pada khususnya dapat mengetahui tahapan capaian apa saja yang telah terlaksana sehingga dapat diketahui kekurangannya dan juga untuk mengambil tindakan dari hasil tahapan capaian dari mahasiswa tersebut.

\section{TINJAUAN PUSTAKA}

\section{Sistem}

Sistem adalah "kumpulan elemen yang saling berhubungan dan saling berinteraksi dalam satu kesatuan untuk menjalankan suatu proses pencapaian suatu tujuan utama" (Sutarman, 2009).

Adapun pengertian sistem "adalah hubungan satu unit dengan unit-unit lainnya yang saling 
berhubungan satu sama lainnya dan yang tidak dapat dipisahkan serta menuju satu kesatuan dalam rangka mencapai tujuan yang telah ditetapkan. Apabila suatu unit macet atau terganggu, unit lainnya pun akan terganggu untuk mencapai tujuan yang telah ditetapkan tersebut" (Jimmy L. Gaol, 2008).

Dari kedua pendapat tersebut dapat disimpulkan bahwa sistem adalah kumpulan dari beberapa elemen atau unit yang beroperasi secara bersama untuk mencapai suatu tujuan utama. Sifat dasar dari sistem adalah :

1. Mencapai tujuan tertentu

2. Adanya kesatuan usaha

3. Adanya suatu kontrol

4. Mempunyai input berupa data

5. Adanya suatu proses

6. Mempunyai input berupa informasi

7. Adanya umpan balik (feed back)

Suatu sistem mempunyai karakteristikkarakteristik atau sifat-sifat tertentu, yaitu mempunyai komponen-komponen (components), batasan sistem (boundary), lingkungan luar sistem (environments), penghubung (interface), masukan (input), keluaran (output), pengolahan sistem (process), dan sasaran sistem (objectives) atau tujuan (goal) (Jogiyanto, 2005).

Suatu sistem terdiri atas komponen-komponen yang saling berinteraksi, yang artinya saling bekerjasama membentuk satu kesatuan. Komponenkomponen sistem dapat berupa subsistem atau bagian-bagian sistem. Setiap subsistem mempunyai sifat-sifat dari sistem yang menjalankan suatu fungsi tertentu dan mempengaruhi proses sistem secara keseluruhan.

Batasan sistem merupakan daerah yang membatasi suatu sistem dengan sistem yang lainnya atau dengan lingkungan luar sistem. Batas sistem ini memungkinkan suatu sistem dipandang sebagai suatu kesatuan. Batas suatu sistem menunjukan ruang lingkup dari sistem tersebut.

Lingkungan luar sistem adalah apapun di luar batas sistem yang mempengaruhi operasi sistem. Lingkungan luar sistem dapat bersifat menguntungkan dan dapat juga bersifat merugikan. Lingkungan luar yang menguntungkan merupakan energi dari sistem dan demikian harus tetap dijaga dan dipelihara. Sedangkan lingkungan luar yang merugikan harus ditahan dan dikendalikan.

Penghubung sistem merupakan media yang menghubungkan subsistem yang satu dengan yang lain. Melalui media ini memungkinkan sumbersumber daya mengalir dari satu subsistem ke subsistem lainnya. Keluaran (output) suatu subsistem dapat menjadi masukan (input) untuk subsistem yang lainnya.

Masukkan (input) adalah energi yang dimasukkan ke dalam sistem. Masukan dapat berupa masukkan perawatan (maintenance input) dan masukkan sinyal (signal input). Masukkan perawatan adalah masukkan agar sistem tersebut dapat beroperasi sedangkan masukkan sinyal adalah masukan yang diproses agar menghasilkan keluaran.

Keluaran sistem merupakan hasil dari energi yang diolah dan diklasifikasikan menjadi keluaran yang berguna.

Suatu sistem dapat mempunyai bagian pengolah yang akan mengubah masukan menjadi keluaran. Suatu sistem produksi akan mengolah masukan berupa bahan baku dan bahan-bahan yang lain menjadi keluaran berupa barang jadi.

Sebuah sistem sudah tentu mempunyai tujuan atau sasaran agar sebuah sistem dapat berguna. Sasaran dari sistem sangat menentukan sekali masukan yang dibutuhkan sistem dan keluaran yang dihasilkan sistem. Suatu sistem dikatakan berhasil bila mengenai sasaran atau tujuannya.

\section{Informasi}

Informasi adalah data yang telah diproses atau data yang memiliki arti (Mcleod, 2001). Informasi adalah data yang diolah menjadi bentuk yang lebih berguna dan lebih berarti bagi yang menerimanya (Jogiyanto, 2001).

Informasi adalah rangkaian data yang mempunyai sifat sementara, tergantung dengan waktu, mampu memberikan kejutan pada yang menerimanya. Intensitas dan lamanya kejutan dari informasi disebut nilai informasi, "informasi yang tidak mempunyai nilai biasanya karena rangkaian data yang tidak lengkap atau kadaluarsa" (Witarto, 2004).

Dari beberapa pengertian tersebut, dapat disimpulkan bahwa informasi merupakan hasil dari pengolahan data menjadi bentuk yang lebih berguna bagi penerimanya dan menggambarkan suatu kejadian-kejadian nyata yang dapat digunakan sebagai alat bantu untuk pengambilan tindakan.

Kualitas dari informasi yang dihasilkan haruslah berisikan tiga hal berikut, yaitu :

1. Tepat pada waktunya (on time), berarti informasi yang datang pada penerimanya tidak boleh terlambat. Informasi yang sudah usang tidak akan mempunyai nilai lagi. Karena informasi merupakan landasan di dalam pengambilan keputusan.

2. Akurat, berarti informasi harus bebas dari kesalahan-kesalahan dan tidak bias atau menyesatkan. Informasi harus jelas mencerminkan maksudnya.

3. Relevan (relevance) berarti informasi tersebut mempunyai manfaat untuk pemakainya (Jogiyanto, 2008).

\section{Sistem Informasi}

Menyangkut pemahaman tentang pengertian sistem informasi, dalam bukunya ia mengutipkan beberapa pendapat para ahli (Agus Mulyanto, 2009), diantaranya :

1. Menurut James Alter, sistem informasi adalah "kombinasi antar prosedur kerja, informasi, orang dan teknologi informasi yang 
diorganisasikan untuk mencapai tujuan dalam sebuah organisasi”".

2. Menurut Bodnar dan Hopwood, sistem informasi adalah "kumpulan perangkat keras dan perangkat lunak yang dirancang untuk mentransformasikan data ke dalam bentuk informasi yang berguna".

3. Menurut Gelinas, Oram dan Wiggins, sistem informasi adalah "suatu sistem buatan manusia yang secara umum terdiri atas sekumpulan komponen berbasis komputer dan manual yang dibuat untuk menghimpun, menyimpan, dan mengelola data serta menyediakan informasi keluaran kepada pemakai".

4. Menurut Turban, McLean dan Waterbe, sistem informasi adalah "sistem yang mengumpulkan, memproses, menyimpan, menganalisis, dan mneyebarkan informasi untuk tujuan spesifik".

5. Menurut Joseph Wilkinson, sistem informasi adalah "kerangka kerja yang mengkoordinasikan sumber daya (manusia, komputer) untuk mengubah masukan (input) menjadi keluaran (informasi), guna mencapai sasaran-sasaran perusahaan".

Dari beberapa definisi diatas, dapat disimpulkan bahwa sistem informasi adalah suatu sistem yang terdiri dari kumpulan komponen sistem, yaitu software, hardware, dan brainware yang memproses informasi menjadi output yang berguna untuk mencapai suatu tujuan tertentu dalam suatu organiasasi.

Untuk mendukung kelancaran suatu sistem informasi dibutuhkan beberapa komponen yang fungsinya sangat vital dalam sistem informasi. Komponen sistem informasi antara lain input, proses, output, teknologi, basis data dan kendali. Secara rinci komponen-komponen sistem informasi dapat dijelaskan sebagai berikut :

1. Input

Input disini adalah semua data yang dimasukkan ke dalam sistem.

2. Proses

Merupakan kumpulan prosedur yang akan memanipulasi input yang kemudian akan disampaikan dalam bagian basis data dan seterusnya akan diolah menjadi suatu output yang akan digunakan oleh si penerima.

3. Output

Merupakan semua keluaran atau hasil dari model yang sudah diolah menjadi suatu informasi yang akan berguna dan dipakai penerima.

4. Teknologi

Teknologi disini merupakan bagian yang berfungsi untuk memasukan input, mengolah input dan mengeluarkan hasil. Ada tiga bagian dalam teknologi ini yang meliputi perangkat keras, perangkat lunak dan perangkat manusia.

5. Basis Data

Merupakan data-data yang saling berhubungan yang disimpan dalam perangkat lunak.

\section{Kendali}

Kendali dalam hal ini merupakan semua tindakan yang diambil untuk menjaga sistem informasi tersebut agar bisa berjalan lancar dan tidak mengalami gangguan.

\section{UML}

Unified Modeling Languange (UML) dirilis tahun 1987 sebagai sebuah metode untuk menggambarkan desain software. Unified Modelling Language (UML) sebagai notasi pemodelan standar industri untuk visualisasi sistem berorientasi obyek dan juga sebagai platform untuk mempercepat proses pengembangan aplikasi. UML menawarkan sebuah standar untuk merancang model sebuah sistem (Sholiq, 2006). Keuntungan menggunakan UML adalah:

1. Software terdesain dan terdokumentasi secara profesional sebelum dibuat, dan dapat diketahui secara persis apa yang nantinya didapatkan.

2. Oleh karena mendesain terlebih dahulu, reusable code dapat dikode dengan tingkat efesiensi tinggi.

3. Lubang dapat diketemukan pada saat menggambar desain.

4. Dengan UML, dapat dilihat gambaran besarnya

UML menjanjikan untuk menghasilkan hasil dengan biaya rendah, software lebih efesien, lebih cepat dipercaya dan hubungan antar bagian yang terlibat menjadi lebih baik. UML terdiri atas beberapa elemen grafik yang dikombinasikan menjadi diagram. Tujuan dari diagram tersebut untuk mempresentasikan bagian sudut pandang dari sistem atau disebut juga dengan model.

Adapun jenis-jenis diagram UML yaitu:

1. Use Case Diagram

2. Sequence Diagram

3. Activity Diagram

4. Class Diagram

5. Object Diagram

6. Collaboration Diagram

7. State Diagram

8. Deployment Diagram

\section{Visual Basic. NET}

Konsep .NET mempunyai tujuan dan visi yang luas karena melalui konsep ini user di seluruh dunia dapat mengakses informasi dalam bentuk file atau program kapan saja, di mana saja, dan dengan menggunakan perangkat apa saja tanpa harus mengetahui lokasi informasi file atau program. Konsep .NET dapat berjalan pada berbagai pearngkat dan berbagai sistem operasi, baik sistem operasi Windows, Unix, Solaris, maupun perangkat PC dengan arsitektur 16 bit, 32 bit, 64 bit, pocket pc, Palm OS, dan sebagainya.

Jika Visual Basic klasik menggunakan VBRUN, C++ menggunakan MSVCRT, dan Java juga menggunakan referensi khusus untuk menjalankan aplikasi yang dibangun, makan Visual 
Basic. NET menggunakan CLR (Command Language Runtime), CLR melakukan manajemen memori, mengeksekusi perintah, menerjemahkan kode perintah, dan berbagai layanan lainnya.

Dalam .NET tidak akan ditemukan komponen yang tercatat dalam registry Windows maupun file DLL, yang selalu menimbulkan konflik satu sama lain dalam referensi pemrograman klasik. Visual Basic .NET sudah meninggalkan semuanya itu dan beralih ke bingkai .NET (.NET Framework).

.NET Framework mempunyai dua komponen utama, yaitu CLR dan Class Library. CLR adalah dasar dari Framework, sedangkan Class Library adalah komponen lain yang menjadi objek dasar pengembangan kode program dan tampilan grafis. Program yang dihasilkan menjadi program dengan inovasi .NET, yaitu ASP.NET, misalnya XML (eXtensible Markup Language) dan HTML (Hypertext Markup Language), yang telah menjadi standar dalam halaman Web.

Tampilan IDE pada Visual Basic . NET lebih modern, elegan, dan efisien. Di dalamnya terdapat banyak control pengembangan program, misalnya : jendela desain form, jendela properties, dan jendela solution explorer. Solution explorer pada Visual Basic adalah perluasan dari project explorer pada Visual Basic klasik (Marlon Leong, 2004).

\section{SAP Crystal Report}

Crystal Report merupakan salah satu paket program yang digunakan untuk membuat, menganalisa, dan menterjemahkan yang terkandung dalam database dalam berbagai jenis laporan. Crystal Report dirancang untuk membuat laporan yang dapat digunakan dengan berbagai bahasa pemrograman berbasis Windows, seperti Visual Basic, Visual $\mathrm{C} / \mathrm{C}++$, Visual Interdev, dan Borland Delphi. Beberapa kelebihan yang dimiliki program Crystal Report, antara lain pembuatan laporan dengan Crystal Report tidak terlalu rumit dan banyak melibatkan kode program, program Crystal Report banyak digunakan karena mudah terintegrasi dengan bahasa lain, fasilitas impor hasil laporan yang mendukung format-format paket program lain seperti Microsoft Office, Adobe Acrobat Reader, HTML, dan sebagainya.

\section{Basis Data}

Basis data adalah suatu susunan atau kumpulan data operasional lengkap dari suatu organisasi atau perusahaan yang diorganisir atau dikelola dan disimpan secara terintegrasi dengan menggunakan metode tertentu menggunakan komputer sehingga mampu menyediakan informasi optimal yang diperlukan pemakainya.

Sistem basis data adalah suatu sistem menyusun dan mengelola record-record menggunakan komputer untuk menyimpan atau merekam serta memelihara data operasional lengkap sebuah organisasi atau perusahaan sehingga mampu menyediakan informasi yang optimal yang diperlukan pemakai untuk proses mengambil keputusan (Marlinda, 2004).

Terdapat empat komponen pokok dalam sistem basis data, yaitu :

1. Data, data di dalam sebuah basis data dapat disimpan secara terintegrasi (integrated) dan data dapat dipakai secara bersama-sama (shared).

2. Hardware (perangkat keras), terdiri dari semua peralatan komputer yang digunakan untuk pengelolaan sistem basis data, berupa :

a. Peralatan untuk penyimpanan basis data, yaitu : secondary strorage (disk, drum, dan lain-lain).

b. Peralatan input dan output.

c. Paralatan komunikasi data, dan lain-lain.

3. Software (perangkat lunak), berfungsi sebagai perantara (interface) antara pemakai dengan data fisik pada basis data.

4. User atau pemakai, pemakai basis data dibagi atas tiga klasifikasi, yaitu:

a. Database Administrator (DBA), orang atau tim yang bertugas mengelola sistem basis data secara keseluruhan.

b. Programmer, orang atau tim yang bertugas membuat program aplikasi, misalnya untuk perbankan, administrasi, akutansi, dan lain-lain.

c. End user, orang yang mengakses basis data melalui terminal dengan menggunakan query language atau program aplikasi yang dibuat oleh programmer.

Pada basis data terdapat tiga jenis data, yaitu :

1. Data operasional, data dari suatu organisasi berupa data yang disimpan di dalam basis data.

2. Data masukan (input data), data dari luar sistem yang dimasukkan melalui peralatan input (misalnya : keyboard) yang dapat mengubah data operasional.

3. Data keluaran (output data), data berupa laporan melalui peralatan output (misalnya : screen, printer, dan lain-lain) sebagai hasil proses dari dalam suatu sistem yang mengakses data operasional.

Keuntungan dalam menggunakan basis data yaitu (Marlinda,2004) :

1. Mengurangi kerangkapan data, yaitu data yang sama disimpan dalam berkas data yang berbeda-beda sehingga update dilakukan berulang-ulang.

2. Mencegah ketidakkonsistenan.

3. Keamanan data dapat terjaga, yaitu dapat dilindungi dari pemakai yang tidak berwenang.

4. Integritas dapat dipertahankan.

5. Data dapat dipergunakan bersama-sama.

6. Menyediakan recovery.

7. Memudahkan penerapan standarisasi. 
8. Data bersifat mandiri (data independance).

9. Keterpaduan data terjaga, memlihara ketrpaduan data berarti data harus akurat. Hal ini sangat erat hubungannya dengan pengontrolan kerangkapan data dan memelihara keselarasan data.

\section{MySQL (MyEs Que El)}

MySQL adalah sebuah Relational Database Management System (RDMS). Program ini bertindak sebagai server yang mengijinkan lebih dari satu pengguna untuk mengakses beberapa basis data.

MySQL sangat populer untuk aplikasi web dan bertindak sebagai komponen basis data dari berbagai macam platform, seperti Linux, BSD, Mac, Windows - Apache - MySQL - PHP, Perl, Python. Kepopularitas dari MySQL dalam aplikasi web berelasi sangat dekat dengan bahasa pemrograman script pada sisi server, seperti PHP, Ruby on Rail. Hubungan antara PHP dan MySQL lebih populer dalam pembuatan suatu Content Management System (CMS), seperti Joomla, Drupal, WordPress.Bahkan Wikipedia dibuat dari kombinasi antara PHP dan MySQL.

Pustaka untuk mengakses MySQL tersedia hampir pada semua bahasa pemrograman dengan beberapa bahasa pemrograman secara spesifis, API.Sebagai tambahan terdapat komponen MySQL untuk ODBC yang disebut sebagai MyODBC. Komponen tersebut mengijinkan bahasa pemrograman yang mendukung interface ODBC untuk melakukan komunikasi dengan basis data MySQL. Pustaka untuk MySQL dan MySQL sendiri kebanyakan dibuat dalam ANSI $\mathrm{C}$ atau ANSI C++ (Syafi'i, 2004).

Fitur utama MySQL adalah ditulis dalam bahasa $\mathrm{C}$ dan $\mathrm{C}++$, menyediakan mesin penyimpanan (engine storage) transaksi dan nontransaksi, server tersedia sebagai pogram yang terpisah untuk digunakan pada lingkungan jaringan client/server, mempunyai sistem password yang fleksibel dan aman, dapat menangani basis data dalam skala besar yaitu sampai 50 juta record (Andi dan Wahana, 2006).

\section{Waterfall}

Metode pengembangan sistem yang digunakan adalah dengan menggunakan metode Waterfall yang merupakan metode yang berfungsi sebagai sebuah mekanisme untuk mengidentifikasi kebutuhan perangkat lunak.

Roger S. Pressman memecah model waterfall menjadi enam tahapan, metode ini memberikan pendekatan-pendekatan sistematis dan berurutan bagi pengembangan piranti lunak. Tahap-tahap yang dilakukan di dalam metode ini menurut Pressman ialah System/Information Engineering and Modeling, Software Requirements Analysis, Design, Coding, Testing/Verification, dan Maintenance.

\section{HASIL DAN PEMBAHASAN \\ Deskripsi Sistem}

Aplikasi yang dibangun menggunakan basis data MySql yang berfungsi sebagai media penyimpanan data, yang terdiri dari dua tabel yaitu tabel mhs_data dan tabel kajur. Untuk dapat mengakses informasi yang ada pada basis data dibuat sebuah aplikasi evaluasi akademik yang dibangun menggunakan Microsoft Visual Basic .NET 2013.

Dalam pengoperasian sistem, admin memiliki hak penuh terhadap sistem mulai dari input data mahasiswa, status mahasiswa, dan ketua program studi. Gambaran aplikasi sistem informasi dapat dilihat pada sub bab selanjutnya yang menjelaskan secara detail sistem informasi ini.

\section{Perancangan Sistem \\ Use Case Diagram}

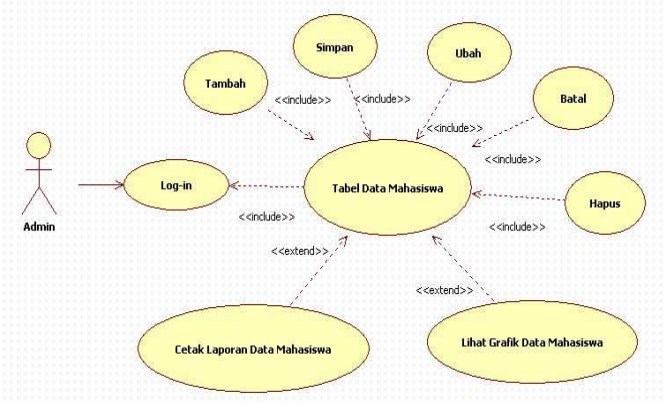

Gambar 1. Use Case Diagram Pengelolaan Data Mahasiswa

\section{Sequence Diagram}

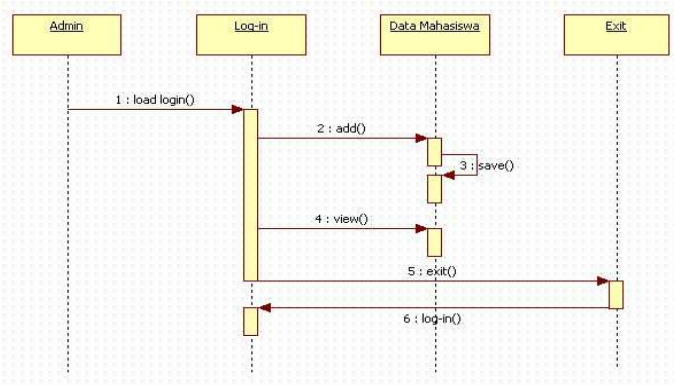

Gambar 2. Sequence Diagram Penyimpanan Data Aktifitas Mahasiswa

\section{Activity Diagram}

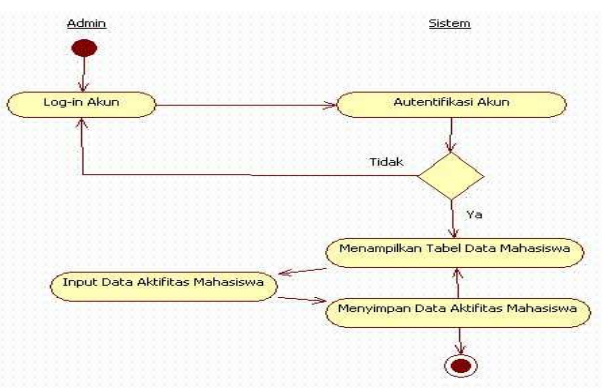

Gambar 3. Activity Diagram Penyimpanan Data Aktifitas Mahasiswa 


\section{IMPLEMENTASI SISTEM \\ Menu Log-in}

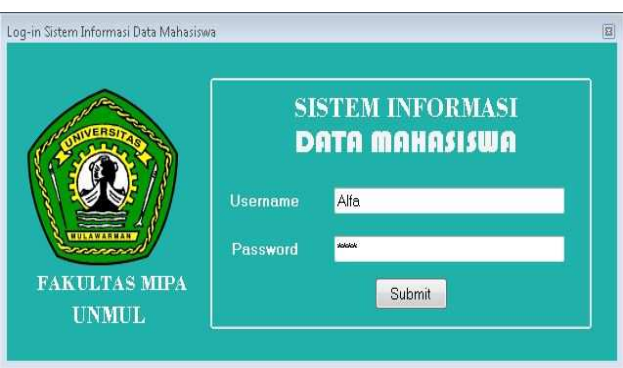

Gambar 4. Tampilan Menu Log-in

Gambar 4 menunjukkan langkah pertama menggunakan aplikasi ini adalah dengan cara $\log$ in. Admin harus mengisi username dan password kemudian klik tombol submit.

\section{Menu Utama}

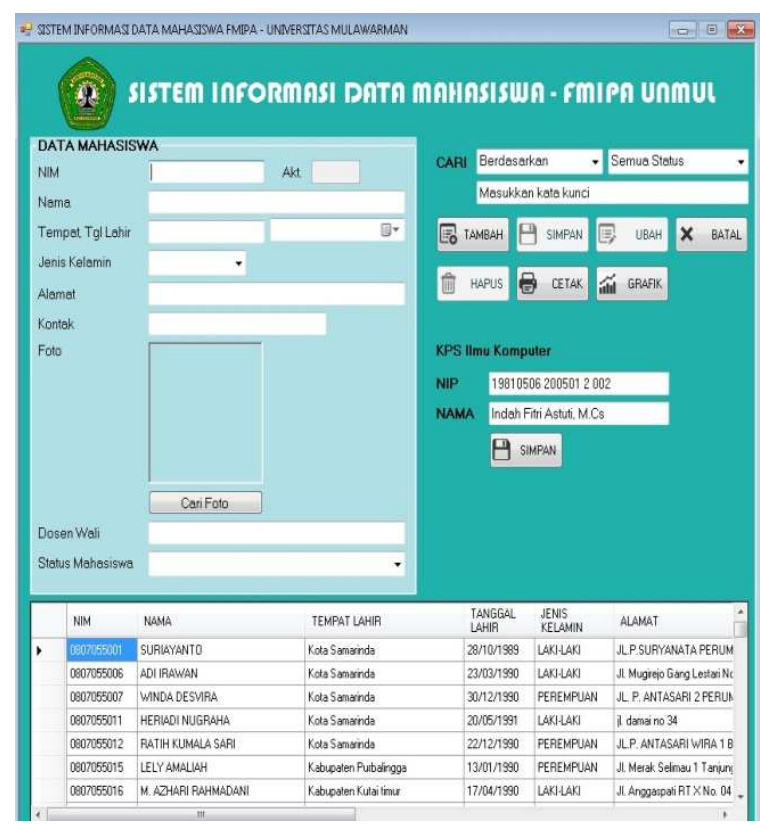

Gambar 5. Tampilan Menu Utama

Gambar 5 menunjukkan menu utama aplikasi yang berisi data mahasiswa meliputi NIM (Nomor Induk Mahasiswa), nama, tempat dan tanggal lahir, jenis kelamin, alamat, kontak, foto, dosen wali, dan status mahasiswa meliputi keterangan KKN (Kuliah Kerja Nyata), PKL (Praktek Kerja Lapangan), seminar 1, pendadaran, lulus, pindah, drop out. Semua data harus dimasukkan satu per satu oleh admin kecuali field angkatan yang akan terisi secara otomatis setelah admin mengisi field NIM dan status mahasiswa yang dalam proses memasukkan data admin hanya memilih status mahasiwa yang ada pada aplikasi ini. Kemudian terdapat field berisi NIP dan nama ketua jurusan yang bisa digunakan untuk mengubah kemudian menyimpan record yang baru.

\section{Menu Laporan Cetak}

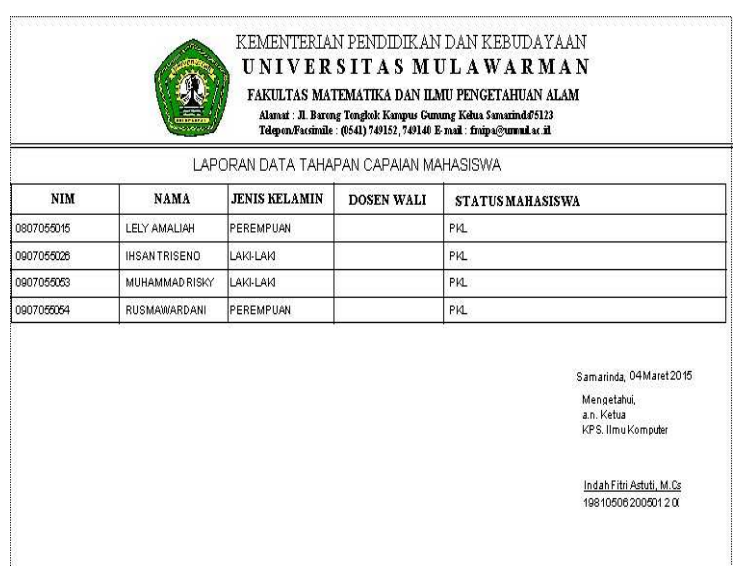

Gambar 6. Tampilan Laporan Cetak PKL

Gambar 6 menunjukkan laporan cetak PKL, dalam penggunaannya sebelum memilih tombol cetak, admin akan memilih data yang akan dicetak melalui tiga filter yang ada pada aplikasi ini, setelah itu baru akan tampil laporan sesuai dengan filter yang digunakan.

\section{Menu Laporan Grafik}
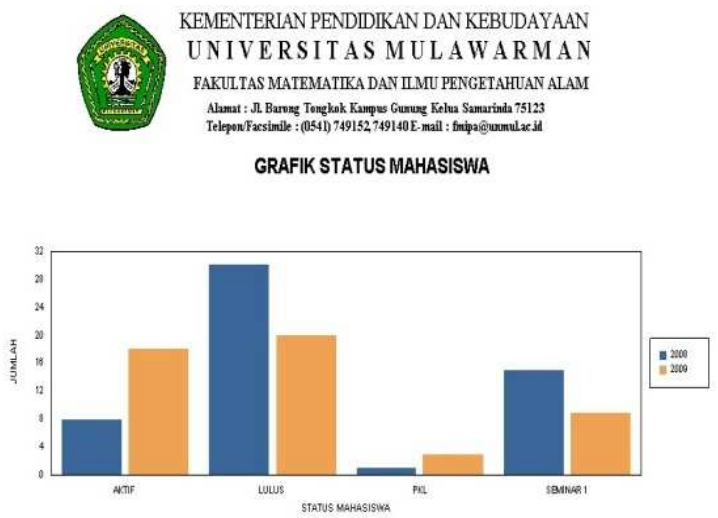

Gambar 7. Tampilan Laporan Grafik Seluruh Angkatan

Gambar 7 menunjukkan laporan grafik status mahasiswa meliputi mahasiswa yang aktif, mahasiswa yang telah lulus, mahasiswa yang telah melaksakan PKL, dan mahasiswa yang telah melaksanakan seminar 1 seluruh angkatan. Pada laporan grafik ini, fitur pencarian pada filter hanya berfungsi pada bagian angkatan saja, jadi laporan grafik yang akan tampil ialah diagram batang perangkatan atau diagram seluruh angkatan dari status mahasiswa.

\section{KESIMPULAN}

Berdasarkan hasil penelitian dan pembahasan yang telah dijabarkan dapat diambil kesimpulan:

1. Telah dibangun Sistem Informasi Data Mahasiswa yang diharapkan dapat membantu tugas program studi. 
2. Sistem Informasi Data Mahasiswa ini membantu mempermudah proses pemantauan belajar mengajar mahasiswa sehingga segala hal yang berkaitan dengan status mahasiswa segera diketahui untuk ditindaklanjuti sesuai dengan ketentuan yang berlaku di Universitas Mulawarman.

\section{DAFTAR PUSTAKA}

[1]. Booch, Grady. 1999. Visual Modeling with Rational Rose 2000 and UML. Boston: Addison-Wesley Professional.

[2]. Gaol, Jimmy L. 2008. Sistem Informasi Manajemen Pemahaman dan Aplikasi. Jakarta: Grasindo.

[3]. Hermawan, Julius. 2004. Analisa Desain dan Pemrograman Berorientasi Obyek dengan UML dan Visual Basic.Net. Yogyakarta: Andi Offset.

[4]. Jogiyanto. 2001. Analisis dan Desain Sistem Informasi: Pendekatan Terstruktur Teori dan Praktik Aplikasi Bisnis. Yogyakarta: Andi Offset.

[5]. Jogiyanto. 2005. Sistem Tekhnologi Informasi. Yogyakarta: Andi Offset.

[6]. Jogiyanto. 2008. Metodologi Penelitian Sistem Informasi. Yogyakarta: Andi Offset.

[7]. Kresnha. (2010). Pengertian Crystal Report dan Kelebihannya. [Online]. Tersedia: http://equilina.blogspot.com/2010/12/penger tian-crystal-report-dan.html. [2 Juni 2014].
[8]. Leitch, Robert A. and Davis, K. Roscoe. 1983. Accounting Informations Systems. New Jersey: Prentice-Hall.

[9]. Leong, Marlon. 2004. Pemrograman Dasar Visual Basic. NET. Yogyakarta: Andi Offset.

[10]. Marlinda, L. 2004. Sistem Basis Data. Yogyakarta: Andi Offset.

[11]. Mcleod. 2001. Sistem Informasi Edisi 7 Jilid 2. Jakarta: Prenhallindo.

[12]. Mulyanto, Agus. 2009. Sistem Informasi Konsep dan Aplikasi. Yogyakarta: Pustaka Pelajar.

[13]. Nailburg and Maksimchuk. 2001. UML for Database Design. Boston: Addison-Wesley Professional.

[14]. Presman, Roger S. 1992. Software Enginering a Practioner's Aproach. New York: McGraw-Hill Companies Inc.

[15]. Sholiq. 2006. Pemodelan Sistem Informasi Berorientasi Objek dengan UML. Yogyakarta: Graha Ilmu.

[16]. Sutarman. 2009. Buku Pengantar Teknologi Informasi. Jakarta : Bumi Aksara.

[17]. Syafi'i, M. 2004. Membangun Aplikasi Berbasis PHP dan MySQL. Yogyakarta: Andi Offset.

[18]. Witarto. 2004. Memahami Sistem Informasi. Bandung: Informatika. 